\title{
12 Haftalık Eşli Dans Çalışmalarının Bazı Fiziksel Uygunluk Parametrelerine Etkisi*
}

\author{
Bahadır OKYAR**, Yunus TORTOP***
}

\section{Özet}

$\mathrm{Bu}$ çalışmada aktif spor yapmayan genç erkeklerde 12 haftalık tango ve salsa çalışma programının, bazı fiziksel uygunluk parametrelerine etkisinin belirlenmesi amaçlandı. Araştırmaya 2014-2015 eğitim-öğretim y1lında, Afyon Kocatepe Üniversitesi’nde öğrenim gören 51 sağlıklı erkek öğrenci gönüllü olarak katılmıştır.

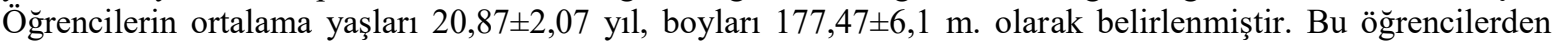
rastgele salsa grubu $(\mathrm{N}=17)$, tango grubu $(\mathrm{N}=17)$ ve kontrol grubu $(\mathrm{N}=17)$ oluşturuldu. Kontrol grubuna herhangi bir egzersiz yaptırılmadı ve günlük yaşamlarına devam etmeleri sağlandı. Deney grubuna ise, 12 hafta, haftada 3 gün, hedef kalp atım hızının \% 50-70'i şiddetinde ve 60-75 dakika arasında eşli dans çalışmaları yaptırıldı. Antrenman öncesinde 10 dakika 1sınma ve antrenman bitiminde 5 dakika soğuma egzersizleri yaptırıldı. Deneklere uygulanan tüm ölçümler ve testler antrenman programı başlamadan iki gün önce (ön test) ve antrenman programı bittikten iki gün sonra (son test) olmak üzere iki kez yapıldı. Araştırma verilerinin analizleri SPSS istatistik paket programında yapıldı. Tüm verilerin aritmetik ortalamaları ve standart sapmaları belirlendi. Deneklerin grup içi ön ve son test değerlerinin arasındaki farklılıkların tespitinde, eşleştirilmiş örneklem t-testi, gruplar arası değerlendirmede ise varyans analizi (ANOVA) ve Tukey çoklu karşılaştırma testi kullanıldı. Anlamlılık düzeyi 0,01 olarak belirlendi. Bu çalş̧̧adaki salsa ve tango gruplarının grup içi ön ve son test sonuçları değerlendirildiğinde, deneklerin ağırlıkları, beden kütle indeksleri, vücut yağ yüzdesi ile bazı deri altı yağ ölçümleri, sırt-bacak kuvveti, esneklikleri, sağ ve sol el kavrama kuvvetleri, anaerobik performans ve aerobik güç $\left(\mathrm{VO}_{2}\right.$ maks) değerlerinde gelişim yönünde anlamlı farklılıklar tespit edilmiştir $(\mathrm{p}<0,01)$. Salsa, tango ve sedanter grupları arasında anova varyans analizine göre; ön test ölçümlerin anlamlı farklılık tespit edilememişken, son test ölçümlerinde ise salsa grubunun tango ve sedanter gruplarına göre vücut yağ yüzdeleri ile aerobik kapasitelerinde anlamlı olarak daha fazla gelişim gösterdiği belirlenmiş̧iir $(\mathrm{p}<0,01)$. Ayrıca salsa grubunun verilerinin tango ve sedanter grup verilerine göre daha fazla gelişim gösterdiği belirlenmiştir. Sonuç olarak salsa ve tango gruplarına uygulanan 12 haftalık eşli dans egzersizlerinin, her iki grupta da kilo kontrolünü, sırt-bacak kuvvetini, el kavrama kuvvetini ve esneklik gelişimini olumlu yönde etkilediği, ayrıca aerobik ve anaerobik verimliliği artırdığı tespit edilmiştir. Bu tür egzersizlerin sadece eğlence amaçlı kullanılmasının yanı sıra, tüm sporcularda psikolojik rahatlama ve sporcular için önemli olan ritim gelişimi açısından da antrenman programları içerisinde yer almasının faydalı olacağı kanısına varıldı.

Anahtar Kelimeler: Dans, Salsa, Tango, Egzersiz, Fiziksel Uygunluk

\section{The Effect of 12 Weekly Couple Dance Activities on Some Physical Fitness}

\section{Parameters}

\author{
Abstract \\ The purpose of this study was to identify the effect of couple dancing activities (Tango, salsa) that applied for \\ 12 weeks to young sedentary men on some physical fitnes parameters. 51 healthy men who studiedat Afyon \\ Kocatepe University in 2014-2015 academic year, participated voluntarily in this research. The mean age of \footnotetext{
olarak sunulmuştur.

** Yüksek Lisans Öğrencisi, Afyon Kocatepe Üniversitesi, Sağlık Bilimleri Enstitüsü, Afyonkarahisar-TÜRKIYE, bahadirokyar@hotmail.com ytortop@hotmail.com
} \\ * Bu çalışma Afyon Kocatepe Üniversitesi, Sağlık Bilimleri Enstitüsü, Beden Eğitimi ve Spor ABD’da Yüksek Lisans Tezi \\ *** Dr. Öğretim Üyesi, Afyon Kocatepe Üniversitesi, Spor Bilimleri Fakültesi, Afyonkarahisar-TÜRKIYYE,
}


the students was $20,87 \pm 2,07$, and mean length was $177,47 \pm 6,1 \mathrm{~cm}$. Volunteers were divided into three groups as Salsa Group $(\mathrm{N}=17)$, Tango group $(\mathrm{N}=17)$ and Control Group $(\mathrm{N}=17)$ as randomly. The volunteers in the control group were not given any exercise program, and continued their daily life. The experimental groups performed couple dance activities three days a week for 12 weeks. Each session lasted for 60-75 minutes, and the intensity of the hearth rates was 50-70\%. The experimental group exercised 10 minutes warm-up and 5 minutes cool-down before and after the main training. All measurements and tests were taken and applied twice as two days before the exercise program (pre-test) and two days after the exercise program (post-test). The data analysis of the research was done by using the statistical SPSS package program, arithmetical average and Standard deviation value of all the data were calculated. The comparison of the post-test and end-test values of the volunteers inside the group was applied with paired samples t-test, the comparison between the groups was applied with Analysis of Varience (ANOVA) and Tukey multiple comparison test. The significance level was observed to be 0.01 . In this study, statistically significant differences were found ( $\mathrm{p}<0,01)$, in body weight, body mass indexes, some subcutaneous fat measurements with body fat percentage, back-leg strength, flexibility, right and lefth and grip, anaerobic and aerobic power $\left(\mathrm{VO}_{2} \mathrm{maks}\right)$, when evaluated the post-test and end-test results between Salsa and Tango groups. According to ANOVA results, statistically no significant differences were found except body fat ratio and aerobic capacity between Control, Salsa and Tango Groups, but Salsa group showed more improvement thanthe Tango and Control group. In conclusion, it was determined that 12 weeks couple dancing exercises caused positive differences in weight control, back-leg strength, hand grip and flexibility, the exercises also increased the anaerobic and aerobic capacity. Besides to be a recreational activity, this type of exercises should be apart of training programs for psychological relaxation and rhythm development of sportathletes.

KeyWords: Dance, Salsa, Tango, Exercise, Physical Fitness

\section{GíRiş}

Dans, vücut yoluyla gösterilen artistik bir anlatım ve bazı fiziksel uygunluk gereksinimlerine sahip olunmas1 gereken bir faaliyettir (Akyıldız ve Açıkada, 2011). Müzik ve dans, insanlık tarihi ile birlikte ortaya çıkmış sanatsal değerlerdir. Kulakları sayesinde doğadaki sesleri duyarak, gözleri sayesinde hareketleri algilayarak etrafindaki ortamı tanımaya çalışan insanoğlu, düşüncesinin yardımıyla seslere, bedeninin hareketlerine ve doğaya hâkim olmayı başarmıştır. Dansı ve onun şekillenişini, tarihsel süreç içerisinde irtibatlı olduğu toplumun sosyo-kültürel konumu açısından değerlendirmek gerekir (Yanık, 2010).

Dans, izleyiciler için yapılan performans dansları ve katılım vurgulu danslar olarak iki kategoride incelenebilir. $\mathrm{Bu}$ kategorilerde bulunan tüm dans türlerinde bedeni tanımak ve nası kullanılacağını öğrenmek mümkündür. Katıllm vurgulu danslardan olan ve izleyiciden ziyade katılımın ön planda olduğu bir dans türü olan üretici dans, bu beklentiyi karşılayacak en uygun türlerden birisidir (Özevin ve Bilen, 2011).

Geçmişte olduğu gibi bu günde fiziksel uygunluğun gerekliliği ve öneminden söz edilmektedir. Doktorlar, bugünkü teknolojinin ilerlemesi ile insan vücudunun fazla yağlanmasından ve günümüz neslinin sinir ve ruhsal dengesizliklerinin artmasından şikâyet etmektedirler. Fiziksel uygunluğun sedanter bireylerde düşük, sporcularda ise yüksek olması çeşitli çevrelerde tartışılmakta ve insanların iyi bir fiziksel uygunluğa sahip olmasının önemi üzerinde durulmaktadır. Fiziksel uygunluk, çevreye olumlu bir şekilde uyum sağlamak olarak tanımlanmaktadır (Zorba, 1999).

Fiziksel uygunluk kas dayanıklılı̆̆ı, kalpsolunum sistemi dayanıklılığı, kas kuvveti, esneklik, sürat, çeviklik, denge, reaksiyon zamanı ve beden kompozisyonunu içermektedir. $\mathrm{Bu}$ nitelikler sportif performans ve sağlık bakımından farklı önemlere sahip olduklarından performansla ilişkili fiziksel uygunluk ve sağlıkla ilişkili fiziksel uygunluk olarak adlandırılmaktadır (Özer ve Özer, 2001).

Yapılan bu çalışmada hız ve hareket açısından birbirinden farklı ve popüler olan salsa ve tango dans türleri belirlenmiştir. $\mathrm{Bu}$ farklı hızlardaki dans türlerinin eğitim çalışmalarının bazı fiziksel uygunluk parametlerine etkisinin hem grup içinde, hem de gruplar arasinda olumlu yönde farklı gelişim göstereceği hipotez edilmiştir. Dolayısı ile bu çalışmada, sedanter genç erkeklerde 12 hafta uygulanan eşli dans türlerinden olan tango ve salsa çalışma 
programının, bazı fiziksel uygunluk parametrelerine etkisinin ortaya konulması amaçlanmiştır.

\section{YÖNTEM}

\section{Katılımcilar}

Araştırmaya 2014-2015 eğitim-öğretim y1lında, Afyon Kocatepe Üniversitesi'nde ögrenim gören 51 sağlıklı erkek öğrenci gönüllü olarak katıldı. Öğrencilerin ortalama

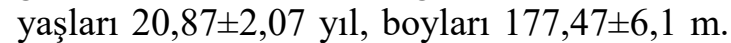
olarak belirlendi. $\mathrm{Bu}$ öğrencilerden rastgele salsa grubu $(\mathrm{N}=17)$, tango grubu $(\mathrm{N}=17)$ ve kontrol grubu $(\mathrm{N}=17)$, oluşturuldu.

\section{Deneysel tasarım}

$\mathrm{Bu}$ çalışmada, sedanter genç erkeklerde 12 haftalık tango ve salsa çalışma programının katılımciları bazı fiziksel uygunluk parametrelerine etkisinin ortaya konulması amaçlanmıştır. Bunun için katılımcılar rastgele yöntemle salsa grubu $(\mathrm{N}=17)$, tango grubu $(\mathrm{N}=17)$ ve kontrol grubu $(\mathrm{N}=17)$ olarak atanmıştır. Kontrol grubuna herhangi bir egzersiz yaptırılmayıp günlük yaşamlarına devam etmeleri istenmiştir. Deney grubuna ise, 12 hafta/haftada 3 gün, maksimal kalp atım eşiği \% 50-70'i şiddetinde ve 60-75 dakika arasında eşli dans çalışmaları yaptırılmıştır. Uygulanan çalışma yöntemine göre düşük şiddette aerobik enerji sisteminin kullanıldığ bir çalışma olarak planlanmıştır. Katılımciların uygulama öncesi (ön test) ve uygulama sonrası (son test) fiziksel uygunluk parametrelerinin belirlenmesinde vücut kompozisyonu, kuvvet, anaerobik ve aerobik performans testleri uygulanmıştır. Deneysel uygulamanın katılımcılar üzerindeki etkisinin belirlenmesi için ön test ve son test değerleri birbiri ile karşılaştırılmıştır.

\section{Deneysel Prosedür}

Çalışmada ilk olarak tüm katılımcılar gönüllü olur formunu doldurmuştur. Daha sonra katılımcıların tanımlayıcı istatistikleri olarak yaş, boy ve ağırlık değerleri tespit edilmiştir. Deneklere uygulanan tüm ölçümler ve testler antrenman programı başlamadan iki gün önce (ön test) ve antrenman programı bittikten iki gün sonra (son test) olmak üzere denekler dinlenik haldeyken iki kez yapılmıştır.
Fiziksel uygunluk testleri olarak; otur-eriş (sit-reach), el kavrama kuvveti, bacak ve sirt kuvveti, dikey siçrama, anaerobik performans, deri altı yağ ölçümü, aerobik güç testleri uygulanmıştır.

Deneklerin esneklik ölçümleri esneklik sehpası kullanılarak otur-eriş (sit-reach) testi ile gerçekleştirilmiştir. El kavrama kuvveti ölçümleri TAKEI GRIP- D marka el dinamometresi ile sirt-bacak kuvveti ölçümleri TAKEI BACK-D marka dijital sırtbacak dinamometresi ile yapılmıştır. Ayrıca elektronik TAKEI JAMP MD marka Jumpmetre kullanılarak dikey sıçrama mesafeleri ölçülmüş ve aşağıdaki formül kullanılarak anaerobik güç hesaplanmıştır (Tamer, 1995).

$\mathrm{P}=\sqrt{ } 4,9(\mathrm{w}) \sqrt{ } \mathrm{D} \mathrm{P}=$ Anaerobik güç $(\mathrm{kg}-\mathrm{m} / \mathrm{sn})$, $\mathrm{W}=$ Vücut ağırlı̆̆ı $(\mathrm{kg}), \mathrm{D}=$ Sıçrama mesafesi (m).

Deri altı yağ ölçümleri Holtain marka skinfold kaliperle, antropometrik ölçüm protokolüne uygun olarak $M$. tricepsbrachii, $M$. bicepsbrachii, M. subscapularis, M. pectoralis, M. quadricepsfemoris kasları ve suprailiac bölgeleri üzerinden alınmıştır (Zorba ve Ziyagil, 1995). Vücut yağ yüzdesinin belirlenmesi için Lange'nin formülü kullanılmıştır (Açıkada ve ark., 1991).

Lange vücut yağ yüzdesi: (Biceps+Triceps+Subscapula+Pectoral+Supra iliac+Quadriceps) x $0.097+3.64$

Aerobik güç testi ölçümleri için ise; "MultistageShuttle Run" testi uygulanmıştır. (Leger ve Lambert, 1982). Bu test için sinyal aralarının her bir dakikada $0,5 \mathrm{~km} / \mathrm{s}$ artan şekilde kalibre edilmiş bir kaset kullanılmış, testin sonunda deneklerin koştukları seviye ve mekik sayısına göre $\mathrm{VO}_{2}$ max hesaplanmıştır.

Antrenman öncesinde 10 dakika 1sinma ve antrenman bitiminde 5 dakika soğuma egzersizleri yaptırılmıştır. Her antrenman ortasinda ve sonunda, boyun bölgesindeki karotid atardamardan $10 \mathrm{~s}$ kalp atım sayıs1 ölçülerek, hedef kalp atım hızına ulașıp ulaşmadığ 1 tespit edilmiştir. Hedef kalp atım hızı aralık değerleri Karvonen formülü kullanılarak belirlenmiştir. Egzersiz sırasında kalp atım hızlarının takibi polar saat (RS800, Finlandiya) ile yapılmıştır. 
Karvonen Formülü: Maksimal kalp atım sayısı $=220$-yaş

Hedef Kalp Atım Sayısı (KAS) $=\%$ Kalp Atım Sayısı $\left(\mathrm{KAS}_{\max }-\mathrm{KAS}_{\mathrm{din}}\right)+\mathrm{KAS}_{\mathrm{din}}$

\section{Tango ve Salsa Eğitimi Egzersiz Programı}

12 hafta boyunca haftada 3 gün hedef kalp atım hızının \% 50-70'i şiddetinde ve 60-75dk arasında eğitim çalışmaları yaptırıldı. Çalışmaların başlarında (ilk 4 hafta) antrenman süresi daha kısa tutuldu. 10 dakikalık bir ısınmanın ardından, 40 dakikalık esas çalışma bölümü ve 10 dakikalık soğuma bölümü şeklinde yapıldı. 2. Ayın başından itibaren yine 15 dakikalık genel bir isınmanın ardından, 45 dakikalık esas bölümü ve 5 dakikalık soğuma bölümü şeklinde çalışmalara devam edildi.

\section{İstatistiksel Analiz}

Araştırma verilerinin analizleri SPSS 18.0 istatistik paket programında yapıldı. Tüm verilerin aritmetik ortalamaları ve standart sapmaları belirlendi. Deneklerin grup içi ön ve son test değerlerinin arasındaki farkl11ıkların tespitinde eşleştirilmiş t-testi, gruplar arası değerlendirmede ise varyans analizi (ANOVA) ve Tukey çoklu karşılaştırma testi kullanılmıştır. Anlamlılık düzeyi 0,01 olarak belirlendi.

\section{BULGULAR}

Tablo 1. Deneklerin Yaş Değerleri

\begin{tabular}{ccccc}
\hline & GRUP & A.O \pm S.D & MiNiMUM & MAKSiMUM \\
\hline \multirow{2}{*}{ YAŞ(N=51) } & SALSA(N=17) & $21,76 \pm 2,7$ & 18 & 26 \\
& TANGO(N=17) & $20,28 \pm 1,3$ & 18 & 23 \\
& SEDANTER(N=17) & $20,65 \pm 1,8$ & 17 & 25 \\
\hline \multirow{2}{*}{ BOY(N=51) } & SALSA(N=17) & $174,76 \pm 7,5$ & 160 & 182 \\
& TANGO(N=17) & $178,22 \pm 4,6$ & 171 & 190 \\
& SEDANTER(N=17) & $179,10 \pm 6,1$ & 160 & 190 \\
\hline
\end{tabular}

Araştırmaya katılan deneklerden salsa grubunun yaş ortalamasının $21,76 \pm 2,7$, tango grubunun yaş ortalamasının $20,28 \pm 1,3$ ve sedanter grubun yaş ortalamasının ise; $20,65 \pm 1,8$ olduğu belirlenmiştir. Deneklerin boy değerleri incelendiğinde ise; salsa grubunun boy ortalamalarının $174,76 \pm 7,5$, tango grubunun boy ortalamalarının $178,22 \pm 4,6$ ve kontrol grubunun boy ortalamalarının ise; $179,10 \pm 6,1$ olduğu görülmüştür.

Tablo 2. Çalışma Öncesi ve Sonrası Grup İçi Ölçüm Değerleri

\begin{tabular}{clcc}
\hline & \multicolumn{1}{c}{ GRUP } & ÖN TEST & SON TEST \\
& \multicolumn{1}{c}{ A.O \pm S.D } & A.O \pm S.D \\
\hline \multirow{2}{*}{ VÜCUT AĞIRLIĞI } & SALSA(N=17) & $68.00 \pm 11,5$ & $64.66 \pm 10,7^{*}$ \\
\cline { 2 - 2 }$(\mathbf{k g})$ & TANGO(N=17) & $73,89 \pm 10,0$ & $71,96 \pm 9,8^{*}$ \\
& SEDANTER(N=17) & $71,75 \pm 9,3$ & $71,57 \pm 9,0$ \\
\hline VÜCUT KİTLE & SALSA(N=17) & $22,13 \pm 2,5$ & $21,06 \pm 2,3^{*}$ \\
İNDEKSİ & TANGO(N=17) & $23,82 \pm 3,2$ & $22,62 \pm 2,8^{*}$ \\
$\left(\mathbf{k g} / \mathbf{m}^{2}\right)$ & SEDANTER(N=17) & $21,72 \pm 2,9$ & $22,29 \pm 2,3$ \\
\hline \multirow{2}{*}{ VÜCUT YAĞ } & SALSA(N=17) & $10,60 \pm 2,1$ & $9,33 \pm 1,7^{*}$ \\
$(\boldsymbol{\%})$ & TANGO(N=17) & $12,05 \pm 3,8$ & $11,36 \pm 3,4^{*}$ \\
& SEDANTER(N=17) & $10,38 \pm 1,6$ & $10,58 \pm 1,5$
\end{tabular}




\begin{tabular}{|c|c|c|c|}
\hline \multirow{3}{*}{$\begin{array}{c}\text { BACAK KUVVETİ } \\
(\mathrm{kg})\end{array}$} & $\operatorname{SALSA}(\mathbf{N}=17)$ & $120,00 \pm 32,9$ & $123,52 \pm 32,3^{*}$ \\
\hline & TANGO(N=17) & $123,94 \pm 31,1$ & $125,97 \pm 30,5^{*}$ \\
\hline & SEDANTER(N=17) & $120,57 \pm 40,5$ & $120,17 \pm 39,9$ \\
\hline \multirow{3}{*}{$\begin{array}{c}\text { SIRT } \\
\text { KUVVETİ } \\
(\mathrm{kg})\end{array}$} & $\operatorname{SALSA}(\mathbf{N}=17)$ & $108,41 \pm 23,4$ & $113,08 \pm 23,7^{*}$ \\
\hline & TANGO(N=17) & $111,71 \pm 22,7$ & $113,55 \pm 22,6^{*}$ \\
\hline & SEDANTER(N=17) & $104,95 \pm 22,5$ & $105,51 \pm 22,2$ \\
\hline \multirow{3}{*}{$\begin{array}{c}\text { SAĞ PENÇE } \\
\text { KUVVETİ } \\
(\mathrm{kg})\end{array}$} & $\operatorname{SALSA}(\mathbf{N}=17)$ & $43,21 \pm 8,6$ & $46,25 \pm 7,7^{*}$ \\
\hline & TANGO(N=17) & $48,13 \pm 6,0$ & $49,61 \pm 5,6^{*}$ \\
\hline & SEDANTER(N=17) & $47,57 \pm 7,2$ & $47,57 \pm 6,8$ \\
\hline \multirow{3}{*}{$\begin{array}{c}\text { SOLPENÇE } \\
\text { KUVVETİ } \\
(\mathbf{k g})\end{array}$} & $\operatorname{SALSA}(\mathbf{N}=17)$ & $41,65 \pm 6,9$ & $45,20 \pm 6,8^{*}$ \\
\hline & TANGO(N=17) & $45,72 \pm 5,2$ & $46,92 \pm 4,9^{*}$ \\
\hline & SEDANTER(N=17) & $42,43 \pm 7,2$ & $42,23 \pm 6,1$ \\
\hline \multirow{3}{*}{$\begin{array}{l}\text { ESNEKLİK } \\
(\mathrm{cm})\end{array}$} & $\operatorname{SALSA}(\mathbf{N}=17)$ & $21,94 \pm 7,3$ & $23,88 \pm 7,2^{*}$ \\
\hline & TANGO(N=17) & $23,44 \pm 9,7$ & $25,39 \pm 9,6^{*}$ \\
\hline & SEDANTER(N=17) & $26,35 \pm 6,7$ & $26,50 \pm 6,7$ \\
\hline \multirow{3}{*}{$\begin{array}{c}\text { DÍKEY SIÇRAMA } \\
(\mathbf{c m})\end{array}$} & $\operatorname{SALSA}(\mathbf{N}=17)$ & $47,88 \pm 11,7$ & $51,35 \pm 11,5^{*}$ \\
\hline & TANGO(N=17) & $49,89 \pm 7,8$ & $51,61 \pm 7,6^{*}$ \\
\hline & SEDANTER(N=17) & $52,95 \pm 8,9$ & $52,90 \pm 7,6$ \\
\hline \multirow{3}{*}{$\begin{array}{l}\text { ANAEROBÍK } \\
(\mathbf{k g}-\mathbf{m} / \mathrm{sn})\end{array}$} & $\operatorname{SALSA}(\mathbf{N}=17)$ & $125,63 \pm 23,4$ & $130,19 \pm 23,2 *$ \\
\hline & TANGO(N=17) & $135,60 \pm 17,3$ & $136,23 \pm 15,8$ \\
\hline & SEDANTER(N=17) & $135,78 \pm 13,6$ & $135,62 \pm 13,4$ \\
\hline \multirow{3}{*}{$\begin{array}{l}\text { AEROBİK } \\
\text { (ml/kg/dak) }\end{array}$} & $\operatorname{SALSA}(\mathbf{N}=17)$ & $34,19 \pm 4,93$ & $38,80 \pm 4,7^{*}$ \\
\hline & TANGO(N=17) & $33,44 \pm 6,02$ & $36,79 \pm 5,6^{*}$ \\
\hline & SEDANTER(N=17) & $32,31 \pm 4,07$ & $32,42 \pm 4,1$ \\
\hline
\end{tabular}

$*(\mathbf{p}<\mathbf{0 , 0 1})$

Tablo 2'de salsa, tango ve sedanter gruplarının çalışma öncesi ve sonrası grup içi ölçüm değerleri görülmektedir. Salsa ve tango gruplarının ön ve son test ölçümlerine göre vücut ağırlığı, vücut kütle indeksi, vücut yağ yüzdesi, sırt kuvveti, el kavrama kuvveti ve esneklik değerleri arasında istatistiki açıdan ileri derecede anlamlı farklılı̆̆ın olduğu görülmüştür $(\mathrm{p}<0,01)$. Anaerobik güç ölçümlerinde ise; salsa grubunun ön ve son test değerleri arasında istatistiki açıdan ileri derecede anlamlı farklılık görülürken $(p<0,01)$, tango grubunda anlamlı farklılık olmadığı belirlenmiştir( $p>0,01)$. Kontrol grubunun ön ve son test değerleri arasında ise yapılan test sonuçlarında istatistiki açıdan anlamlı farklı1ık olmadığı tespit edilmiştir ( $p>0,01)$.

\section{TARTIŞMA VE SONUÇ}

Yapılan bu araştırmada salsa ve tango grubundaki deneklerin vücut ağırlığı, vücut kütle İndeksi değerleri ve vücut yağ yüzdeleri ortalamalarının grup içi ön ve son test değerleri arasında istatistiki açıdan ileri derecede anlamlı farklılığın olduğu görüldü $(\mathrm{p}<0,01) . \mathrm{Bu}$ farklılığın kontrol grubunda olmadığı tespit edilmiştir $\quad(p>0,01)$. Literatürde benzer çalışmalar incelendiğinde, semazen eğitimine, bale dansçılarının eğitimine, halk oyunları çalışmalarına, step aerobik çalışmalarına yönelik yapılan egzersizlerde de, çalışma gruplarının kilolarında, vücut kütle indekslerinde ve vücut yağ yüzdesi değerlerinde düşüşe rastlandığ 1 bildirilmiştir (Altunöz, 2010; Gupta ve ark, 2004; İmamoğlu ve ark., 2002; Ocak ve Tortop, 2013; Tortop ve ark., 2013).

Yapılan başka bir araştırmada ise, salsa dans egzersizlerine katılan çalışma grubunun 
$(\mathrm{N}=20)$ vücut ağırlıklarının 1. Ölçümde $65,6 \pm 11.52 \mathrm{~kg}, 2$. ölçümde $64,6 \pm 11.43 \mathrm{~kg}$ olduğu bildirilmiştir. Ancak bu azalmanın istatistiki olarak anlamlı olmadığı, bunun sebebinin de deneklerin sağlı bakanlığ 1 değerlendirme çizelgelerine göre normal kabul edilen VKİ sınırları arasında (Normal VKİ: 18,5-24,9 arası) olmasindan dolay1, değerlerde fazla bir düşüş görülmemesinden kaynaklandığı bildirilmiştir (Türkeri, 2015).

Ünveren (2006), düzenli halk oyunları çalışmalarının bazı fiziksel ve fizyolojik parametrelere etkisini araştırdığ 1 çalışmasında, düzenli egzersiz yapmanın vücut kompozisyonunda yağlı kütlenin azalmasına karşı yağsız kütlenin artmasına sebep olduğunu bildirmiştir.

Başka bir çalışmada, 8 hafta ve haftada 3 gün, maksimal nabzın \% 50-60 şiddetinde, 45-55 dakika yapılan step-aerobik egzersizlerinin sonucunda, deneklerin hem vücut kütle indekslerinde, hem de vücut ağırlıklarında anlamlı azalma bulamamışlardır (Kurt ve ark., 2008). Bu farkl1lık, egzersizin daha kısa zamanda tamamlanmış olmasından kaynaklanmış olabileceğini düşündürmektedir.

Aerobik egzersizler farklı sürelerde, değişik yaş gruplarında uygulanmış ve vücut yağ yüzdelerinde istatistiki olarak anlamlı düşüşler bildirilmiştir (Kin ve ark., 1996; Mccord ve ark., 1989; Kaya, 2011; Saçaklı ve ark., 1997).

Araştırmacılar tarafından yapılan benzer çalışmalarda da görüldüğü gibi, sonuçlar bu çalışmadaki bulgularla benzerlik göstermekte ve orta şiddetteki aerobik egzersizlerin vücut ağırlı̆̆ında, vücut kütle indeksi değerlerinde ve vücut yağ yüzde oranlarında düşüşe sebep olduğunu ortaya çıkarmaktadır. Bu sonuçlar, orta şiddetteki egzersizlerde yağların oksidasyona uğrayarak enerji kaynağı olarak kullanılmasından dolayı, vücut ağırlığında ve vücut yă̆ yüzdesinde azalmanın olacağ1 görüşünü desteklemektedir.

Yapılan bu araştırmada deneklerin kuvvet özelliklerine yönelik yapılan sırt, bacak ve el pençe kuvveti ölçümlerinde salsa ve tango gruplarındaki deneklerin grup içi ön ve son test değerleri arasında istatistiki açıdan ileri derecede anlamlı farklılığa rastlanmıştır $(\mathrm{p}<0,01)$. Kuvvet değerlerindeki bu anlamlı artışın kontrol grubunda olmadığ görülmüştür $(\mathrm{p}>0,01)$. Ayrıca sağ ve sol pençe kuvvetlerindeki artışın salsa da tangoya göre fazla olduğu belirlenmiştir.

Literatür incelendiğinde; farklı branş ve yaş gruplarında yapılan aerobik egzersizleri sonucunda, kuvvet değerlerine yönelik yapılan ölçümlerde artışlar bildirilmiştir (Blake ve ark. 2000; Kurt ve ark., 2010; Koenig ve ark., 1999; Ocak ve Tortop, 2013; Ünveren, 2006; Zorba ve ark., 2000a).

Salsa da sağ ve sol pençe kuvvetlerindeki artışın tangoya göre fazla olması kolların hareketli olması ve hareketlerin gövde seviyesinde gerçekleşmesinden kaynaklandığ 1 düşünülmektedir.

Çalışmada esneklik ölçümleri incelendiğinde, salsa ve tango grubundaki deneklerin grup içi ön ve son test değerleri arasında istatistiki açıdan ileri derecede anlamlı farklılığa rastlanmış $(p<0,01)$ ancak, bu farklılığın kontrol grubunda olmadığı belirlenmiştir $(\mathrm{p}>0,01)$.

Literatürde benzer çalışmalar incelendiğinde, cimnastik, step aerobik ve yapılan aerobik egzersiz çalışmalarında, çalışma gruplarının esneklik değerlerinde artışa rastlandığ 1 bildirilmiştir (Çolakoğlu ve Karacan, 2006; Karacan, 2005; Kin ve ark., 2006; Zorba ve ark., 2000b, Yıldız ve ark., 2009).

$\mathrm{Bu}$ sonuçlara göre, eşli dans eğitimi çalışmalarının, eklemlerin hareket sınırlarını zorlayarak, eklem hareketliliğini geliştirdiği söylenebilir.

$\mathrm{Bu}$ çalışmada salsa grubundaki deneklerin anaerobik ölçüm değerlerinde, grup içi ön ve son test değerleri arasında istatistiki açıdan ileri derecede anlamlı farklılığın olduğu görülmüştür $(p<0,01)$. Bu farklılığın tango ve kontrol grubunda olmadığ $\breve{1}_{1}$ belirlenmiştir $(\mathrm{p}>0,01)$. Bu durum salsa dans türünün, tango dans türüne göre daha hareketli ve hızlı tempoda uygulanmasi durumu ile açıklanabilir.

İncelenen benzer çalışmalarda farklı yaş grubunda ve branşlarda yapılan aerobik egzersizlerin çalışma grupların anaerobik güçlerinde olumlu yönde değişikliklere sebep 
olduğunu bildirmişlerdir (Çolakoğlu ve Karacan, 2006; Karacan ve ark., 2004).

Dans çalışmalarında kollar ve bacaklar daha dinamiktir ve izotonik hareket kalıplarında kullanılmaktadır. $\mathrm{Bu}$ tür hareketler dansta oldukça fazla tekrarlandığından çalışan kişilerin anaerobik güçleri önemli düzeyde geliştirilebileceği düşünülmektedir. 12 haftalık eşli dans egzersizleri sonucunda Lewis formülüne göre yapılan anaerobik güç hesaplamasında vücut ağırlığının kullanılması, anaerobik güç açısından sayısal değerlerde özellikle tango grubunda anlamlı artışın gerçekleşmediğini düşündürmüştür.

$\mathrm{Bu}$ çalışmada aerobik ölçüm değerlerinin salsa ve tango grubundaki deneklerin aerobik ölçümlerinde, grup içi ön ve son test değerleri arasında istatistiki açıdan ileri seviyede anlamlı farklılığa rastlanmıştır $(p<0,01)$. Bu farklılığın sedanter grubunda olmadığ 1 belirlenmiştir $(p>0,01)$.

İncelenen pek çok çalışmada da orta şiddette düzenli olarak yapılan aerobik egzersizlerin $\mathrm{VO}_{2}$ maks'yi arttırdığ 1 belirtilmektedir. $\mathrm{Bu}$ egzersizleri gerek normal, gerek obez insanlar uygulamış olsun, kapasitenin $\% \quad 50-80$ şiddetinde aerobik egzersiz uygulanan çalışmalarda $\mathrm{VO}_{2}$ maks değerlerinde artış bildirildiği görüldü (Kurt ve ark., 2010; Mccord ve ark.,1989).

Woodby (1993), $\mathrm{VO}_{2}$ maks değerlerindeki artışın, kas kuvvetinin dayanıklılığı ile doğru orantılı olduğunu bildirmiştir.

$\mathrm{Bu}$ çalışmadaki $\mathrm{VO}_{2}$ maks değerlerindeki artış istatistiki açıdan anlamlı olmasına rağmen, diğer benzer çalışmalardaki artış değerlerinden düşük bulunmuştur. $\mathrm{Bu}$ durum eşli dans eğitiminde, özellikle tango çalışmalarındaki \% yüklenmenin daha düşük şiddette ve dinlenme aralıklarının fazla olmasından kaynaklanmış olabileceğini düşündürmektedir.

Yapılan bu çalışmada salsa, tango ve sedanter grupları arasındaki anova varyans analizi incelendiğinde; vücut yağ yüzdesi ile aerobik kapasite dışındaki tüm parametrelerde istatistiki olarak anlamlı bir farkl1lı tespit edilemedi. Ancak salsa grubunun verilerinin tango ve sedanter grup verilerine göre daha fazla gelişim gösterdiği belirlendi. Bu durum salsa hareketlerinin tangoya göre daha hızlı bir ritim ile yapılmasından kaynaklandığ düşünülmektedir.

$\mathrm{Bu}$ çalışmanın sonuçları ile benzer diğer çalışmalar incelendiğinde, düzenli eşli dans çalışmasına katılan bireylerin bazı fiziksel ve fizyolojik özelliklerinin olumlu yönde geliştiği görülmektedir.

$\mathrm{Bu}$ çalışmada farklı hızlardaki dans türlerinin eğitim çalışmalarının, bazı fiziksel uygunluk parametlerine etkisinin hem grup içinde, hem de gruplar arasinda olumlu yönde farklı gelişim göstereceği hipotez edilmiştir. Çalışma sonunda; 12 haftalık eşli dans egzersizlerin ağırlık kontrolünü, sırt kuvvetini, el kavrama kuvvetini ve esneklik gelişimini olumlu yönde etkilediği, ayrıca aerobik ve anaerobik verimliliği artırdığı tespit edilmiştir. $\mathrm{Bu}$ tür egzersizlerin dans branşına özgü eğlence ve yarışma amaçlı uygulanmasının yanı sıra, tüm sporcularda psikolojik rahatlama ve sporcular için önemli bir gereksinim olan, ritim gelişimi açısından da antrenman programları içerisinde yer alması faydalı olacaktır.

\section{KAYNAKÇA}

Açıkada C, Ergen E, Alpar R, Sarpyener K. (1991). Erkek sporcularda vücut kompozisyonu parametrelerinin incelenmesi. Spor Bilimleri Dergisi, 2(2): 11 .

Akyıldız, M., \& Açıkada C. (2011). Fitness Related Parameters of Classical Ballet Dancers as Athletes Performing Art: A Brief Review, Hacettepe J. of Sport Sciences, 22 (1), 33-42

Altunöz, E. (2010). Sekiz Haftalık Step-Aerobik Çalışmasının 12-14 Yaş Arası Kız Öğrencilerde Săglıkla İlişkili Fiziksel Uygunluk Değişkenleri Üzerine Etkisinin Araştırılmast- Yüzüncü Y1l Üniversitesi, Sağlık Bilimleri Enstitüsü, (Yayınlanmamış Yüksek Lisans Tezi). VAN

Blake, A., Miller, W. C., \& Brown, D. A. (2000). Adiposity does not hinder the fitness responseto exercise training in obese women, The Journal of Sports Medicine and Physical Fitness, 40(2): 107-117. 
Çolakoğlu F. F., \& Karacan, S. (2006). Genç bayanlar ile orta yaş bayanlarda aerobik egzersizin bazı fizyolojik parametrelere etkisi. Kastamonu Eğitim Dergisi. Cilt:14 No:1 s277-284

Gupta, A., Fernihough, B., Bailey, G., Bombeck, P., Clarke, A., \& Hopper, D. (2004). An evaluation of differences in hiperexternalrotations trengt hand range of motion between female dancers and non-dancers", Br J Sports Med. Dec, 38(6):778-783

İmamoğlu, O., Akyol, P., \& Bayram, L. (2002). Sedanter Bayanlarda 3 Aylık Egzersizin Fiziksel Uygunluk, Vücut Kompozisyonu ve Bazı Kan Parametreleri Üzerine Etkisi, 7. Uluslararası Spor Bilimleri Kongresi, 27-29 Ekim.

Karacan, S., Çolakoğlu, F.F., \& Erol, E. (2004). Obez orta yaş bayanlar ile menopoz dönemindeki bayanlarda aerobik egzersizin bazı fiziksel uygunluk değerlerine etkisi, Erciyes Üniversitesi Sağlık Bilimleri Dergisi (E.Ü.Journal of Health Sciences), 13(1): 35-42).

Karacan, S. (2005). Theeffect of 3 and 6 month callisthenic exercise inmenopausal women on some physical finess parameters. The 46th ICHPER SD. Anniversary World Congress. November 9-13

Kaya, İ. (2011). Zeybek ve Horon Halkoyunları Topluluklarında Oynayan Erkek Halkoyuncuların Vücut Yağ Yüzdeleri ve Fizyolojik Özelliklerinin Karşılaştırılması, Selçuk Üniversitesi, Beden Eğitimi ve Spor Bilimleri Dergisi,13(3): 378-382

Kin, A.İ., Koşar, N. \& Tuncel, F. (1996). 8 Haftalık Step Aerobik Dansın Üniversiteli Bayanların Fiziksel Uygunluğuna Etkisinin Karşılaştırılması, Hacettepe Üniversitesi Spor Bilimleri Dergisi, Cilt 7, Say1 3, s21-31

Koenig, M.J., Dave, M.J., Thomas E.D., \& Jerry, W.C. (1999). Theeffect of benchstep aerobics on muscular strength, power and endurance, The Journal of Strengthand Conditioning Research, 9(1): 43-46.
Kurt, S., Hazar, S., İbiş, S., Albay, B., \& Kurt, Y. (2010). Orta yaş sedanter kadınlarda sekiz haftalı step-aerobik egzersizinin bazı fiziksel uygunluk parametrelerine etkilerinin değerlendirilmesi. Uluslararasi İnsan Bilimleri Dergisi.7(1) 665-674

Leger L. A, Lambert J. A. (1982) maximalmultistage $20 \mathrm{~m}$ shuttlerun test topredict VO2 max. EuropeanJournal of Applied Physiology, 49: 1-5.

Mccord, P., Nichols, J., \& Patterson, P. (1989). The Effect of Low İmpact Dance Training on Aerobic Capacity, Submaximal Heart Ratesand Body Composition of CollegeAged Females, J Sport MedPhysFitness, 29 (2): 184-188.

Ocak, Y., \& Tortop, Y. (2013). Kadınlarda Halk Oyunları Çalışmalarının Bazı Fiziksel Uygunluk Parametreleri Üzerine Etkisinin İncelenmesi. Spor ve Performans Araştırmaları Dergisi. Samsun: Cilt / Vol : 4 Sayı / No :1

Özer, D.S., \& Özer M. K. (2001). Çocuklarda Motor Gelişim, Nobel Yayın Dağıtım Ankara.

Özevin Tokinan, B., \& Bilen, S. (2011). Yaratıc1 Dans Etkinliklerinin Motivasyon, Özgüven, Öz yeterlik ve Dans Performans1 Üzerindeki Etkileri. Hacettepe Üniversitesi, Eğitim Fakültesi Dergisi, 40: s. 363-374

Saçaklı, H., Öztürk, M., \& Saçaklı, M. (1997). Aerobik Egzersiz ve Diyetin Obez Bayanlarda Antropometrik Ölçümlere ve Solunum Parametrelerine Etkisi, Spor Hekimliği Dergisi, 32:43-53

Tamer K. (1995). Sporda Fiziksel-Fizyolojik Performansın Ölçülmesi ve değerlendirilmesi, Türkerler Kitapevi, Ankara. s. 138-140.

Tortop, Y., Aksu, A. İ, \& Gümüş, H. (2013). Semazen Eğitimi Çalışmalarının Bazı Fiziksel Uygunluk Parametreleri Üzerine Etkisinin Belirlenmesi1- Uluslararası Hakemli Akademik Spor Sağlık Ve Tip Bilimleri Dergisi. Ekim-Kasım-Aralık Say1:09 Cilt: 3 s.47-58

Türkeri, C. (2015). On iki Haftalık Salsa Dans Çalışmalarının Vki ve Statik Dengeye 
Etkisi. Çukurova Üniversitesi Ĕgitim Fakültesi Dergisi, 44(1), s.01-22.

Ünveren, A. (2006). Düzenli halk oyunları çalışmalarının bazı fiziksel ve fizyolojik parametrelere etkisi. Beden Ĕ̈itimi ve Spor Bilimleri Dergisi, 8(1), 28-35

Woodby, S. (1993). Oxygen cost of aerobicdance bench stepping at three heights, The Journal of Strengt hand Conditioning Research, 7(3): 163-167

Yanık, E. (2010). Dans ve İletişim. (Yayınlanmamış Yüksek Lisans Tezi). Üniversitesi Sosyal Bilimler Enstitüsü. Sakarya

Yıldız, M., Başpınar, S. G., Ocak, Y., Akyıldız, Z., \& Bozdemir, M. (2018). Egzersiz öncesi titreşimli foam roller uygulamasının sürat çeviklik, dikey sıçrama ve esneklik üzerine etkisi. Spor ve Performans Araştırmaları Dergisi, 9(3), 216-225.

Zorba, E. (1999). Herkes İçin Spor ve Fiziksel Uygunluk, Gazi Kitapevi, Ankara. s.46

Zorba E, Ziyagil M. A. (1995). Vücut Kompozisyonu ve Ölçüm Metotları. Erek Ofset, Trabzon. s.252-282,

Zorba, E., Yıldırım, S., Saygın, Ö., \& Yaman, R. (2000a). Orta yaşlı sedanterbayanlarda step çalışmasının bazı fizyolojik, motorik ve yapısal değerlere etkisi, 1. Gazi Üni. Beden Eğitimi ve Spor Bilimleri Kongresi, Ankara.

Zorba, E., Yaman, R., Yıldırım, S., \& Saygın, Ö. (2000b). 18-24 yaş grubu sedanter bayan öğrencilerde 8 haftalık step uygulamasının bazı fiziksel uygunluk ve antropometrik değerlere etkisi, 1. Gazi Beden Eğitimi ve Spor Bilimleri Kongresi, Ankara. 